
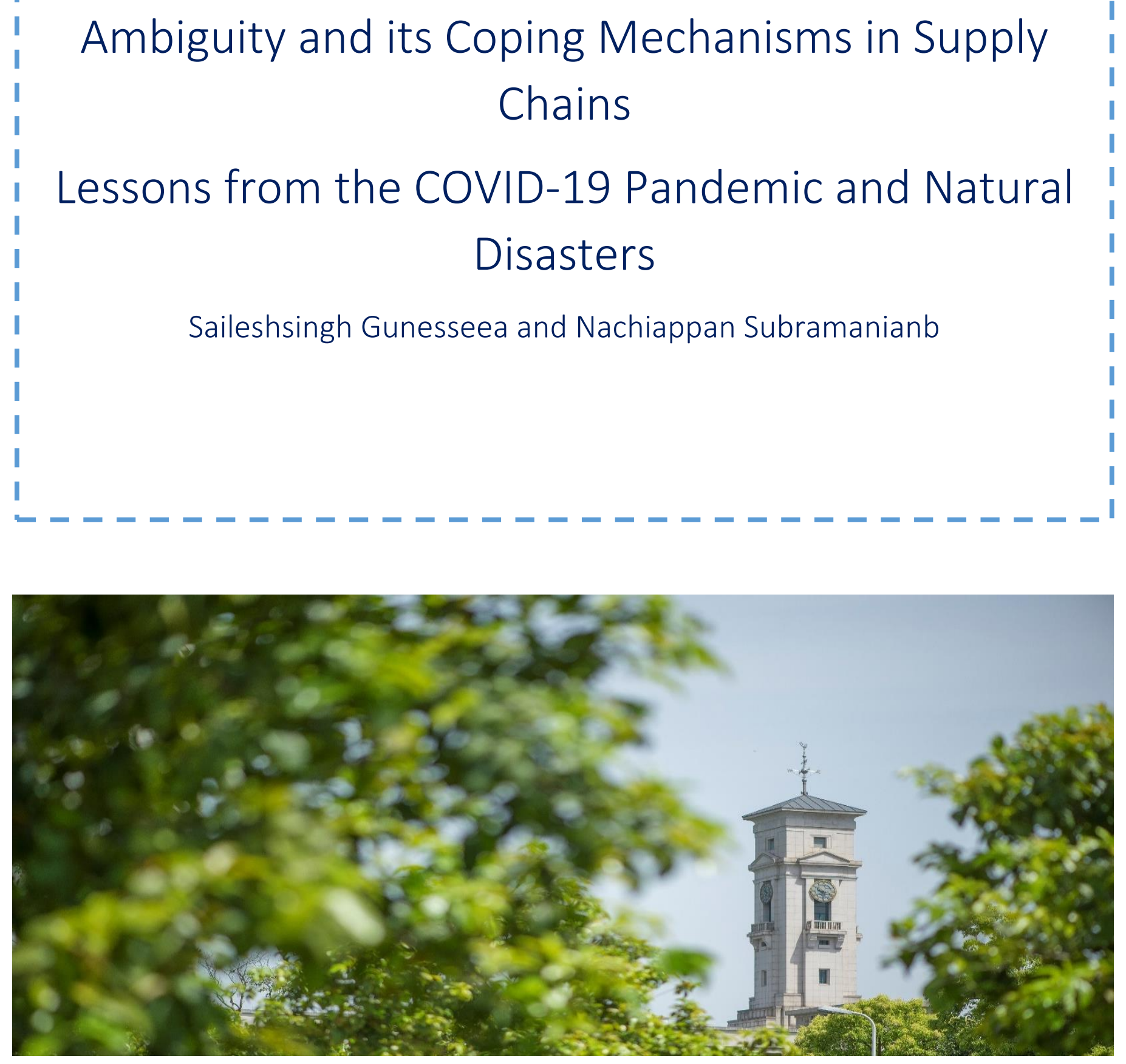
University of Nottingham Ningbo China, 199 Taikang East Road, Ningbo, 315100, Zhejiang, China.

First published 2020

This work is made available under the terms of the Creative Commons Attribution 4.0 International License:

http://creativecommons.org/licenses/by/4.0

The work is licenced to the University of Nottingham Ningbo China under the Global University Publication Licence:

https://www.nottingham.edu.cn/en/library/documents/researchsupport/global-university-publications-licence-2.0.pdf 


\title{
Ambiguity and its Coping Mechanisms in Supply Chains Lessons from the COVID-19 Pandemic and Natural Disasters
}

\author{
Saileshsingh Gunessee ${ }^{\mathrm{a}}$, Nachiappan Subramanian ${ }^{\mathrm{b}, *}$ \\ a Nottingham University Business School China, University of Nottingham Ningbo China, 199 \\ Taikang East Road, Ningbo 315100, China \\ ${ }^{b}$ School of Business, Management and Economics, University of Sussex, Falmer, Brighton \\ BN1 9SL, UK
}

* Corresponding author. Tel.: +44 1273872982.

E-mail: N.Subramanian@sussex.ac.uk (N. Subramanian). 


\begin{abstract}
Purpose - The first purpose of this paper is to situate and conceptualise ambiguity in the operations management $(\mathrm{OM})$ literature, as connected to supply chain decisionmaking (SCDM). The second purpose is to study the role of ambiguity-coping mechanisms in that context.

Design/methodology/approach - This research uses behavioural decision theory to better embed ambiguity in a generic SCDM framework. The framework explicates both behavioural and non-behavioural antecedents of ambiguity and enables us to also ground the 'coping' mechanisms as individual and organisational level strategies. Properties of the framework are illustrated through two 'ambiguous' events - 2011 Thai Flood and Covid-19 pandemic.

Findings - Three key findings are documented. First, ambiguity is shown to distinctively affect supply chain decisions and having correspondence with specific coping mechanisms. Second, our conceptual framework shows how individual coping mechanisms can undermine rational-based organisational coping mechanisms, leading to 'sub-optimal' (poor) supply chain decisions. Third, our study highlights the positive role of visibility but surprisingly organisational 'experiential' learning is imperfect, due to the focus on 'similar' past experience and what is known.

Originality/value - The paper is novel in two ways. First, it introduces ambiguity an often neglected concept in operations management - into the supply chain lexicon, by developing a typology of ambiguity. Second, ambiguity-coping mechanisms are also introduced as both individual and organisational strategies. This enables the study to draw distinctive theoretical and practical implications.
\end{abstract}

Keywords: Ambiguity, Coping Mechanisms, Supply Chain Decision-Making, Behavioural Decision Theory, Covid-19.

Paper type: Research paper 


\section{Introduction}

The operations management $(\mathrm{OM})$ literature recognises that a firm's supply chain is subject to risk and uncertainty (Chopra and Sodhi, 2004; Simangunsong et al., 2016). Not surprisingly supply chain risk is well documented and studied in the literature, spawning a whole sub-field in supply chain risk management (Kouvelis et al., 2012; Wieland and Wallenburg, 2012). Though the literature has also highlighted the need to consider catastrophic risk or the highly improbable (Knemeyer et al., 2009) and resilience instead of just risk (Fiksel et al., 2015), it still suffers from a lacuna. This has to do with the neglect of 'ambiguity' in the OM literature.

Ambiguity is the imprecision involved in situations when the decision-maker is making a judgement, assessment or forecasts (March, 1994). As it is distinct from risk and uncertainty (Aven, 2014; March, 1988), supply chain decision-making (SCDM) under ambiguity should also be distinct. For example, SCDM under disruptions, can be defined as ambiguous because the situational context is characterised by a lack of clarity and consistency. The 2019/20 Covid-19 pandemic bears such characteristics. Once it unfolded globally, lockdowns in many parts of the world and highly volatile demand made supply chain decisions difficult, due to the resultant information incompleteness, which in particular, put the medical equipment supply chain under a lot of strain (Bloomberg, 2020; Washington Post, 2020).

While disruptions are good candidates to describe 'supply chain under ambiguity', an organisation's operations are also subject to ambiguity under normal circumstances. This is due to its supply chain being complex, global and importantly fallible due to the human factor, with its well-known errors or biases. As such many supply chain decisions, such as procurement, capacity allocation, contracting, scheduling, 
postponement and demand forecasting, can be modelled as decision-making problems under ambiguity.

The first aim of this paper is to uncover how far the neglect of ambiguity goes and contribute to its theoretical conceptualisation within the OM literature. A second objective is to investigate the role of 'ambiguity-coping' mechanisms in the supply chain context. We argue that ignoring ambiguity can be impactful not just because of the disastrous effect of ignoring the highly improbable (Craighead et al., 2007; Roberto et al., 2006), but problematic for the conclusion that risk management tools or strategies can deal with ambiguous situations and disruptions (Colicchia et al., 2010; Simchi-Levi et al., 2014). A supply chain risk management (SCRM) approach to carry out risk assessment tend to use traditional probabilistic approaches (Aven, 2014, p.163; Colicchia et al., 2010; Wieland and Wallenburg, 2012). For example, to quantify supply chain risk, the probability of an event and its business outcomes are used to compute its expected value (Christopher and Peck, 2004; Manners-Bell, 2014).

However, these are deemed as narrow and inadequate. The 'reductionist' risk approach cannot adequately capture ambiguous threats as it relies on 'identifiable' statistical information (Fiksel et al., 2015). It is often the case that unclear information and signals are ignored, with a focus shifting to risk. Roberto et al. (2006) provide a few examples of companies that walked that path with disastrous impact, such as Kodak dismissing early unclear signals of the decline of the film business and Merck's misjudgement of the reputational threat following ambiguous data about the painkiller Vioxx.

Studies that do make the risk and ambiguity distinction clear are scant (see Ancarani et al., 2013; Dong et al., 2016; Gray and Handley, 2015; Lawson and Potter, 2012; Natarajan et al., 2012). Still these are either, narrow in their theoretical 
treatment (Natarajan et al., 2012), or focus on narrowly defined types of ambiguity (Dong et al., 2016; Gray and Handley, 2015; Lawson and Potter, 2012). Ambiguity can be distinct not only from risk but from uncertainty as well (March, 1994, pp.178179), it is multifaceted (March, 1988, pp.12-13), and as argued in this study can be ‘behaviourally’ grounded (Dhami, 2016).

Noting these lacunae, this paper contributes to the literature in several ways. First, drawing from 'behavioural decision theory', it proposes a generic supply chain decision-making (SCDM) framework to embed ambiguity in the supply chain context with behavioural foundations. The framework allows us to develop a typology of ambiguity. Extant literature, have shown a surprising neglect for ambiguity and have rarely modelled it with a behavioural lens. We seek to remedy this as our framework explicates both behavioural and non-behavioural antecedents. As such our paper also contributes to the bourgeoning behavioural operations management literature (Donohue et al., 2019, 2020; Gino and Pisano, 2008), whose treatment of ambiguity is also limited. Therefore, our work reads as an attempt to conceptualise ambiguity in a supply chain context with behavioural underpinnings.

The second contribution of our study is the introduction of the concept of 'coping mechanisms' to the supply chain lexicon. While 'organisational' coping strategies consist of mitigation (minimising ambiguous disruptions) and preparedness (resilience and robustness) - strategies which are well-documented in the OM literature (Pettit et al., 2019; Simangunsong et al., 2012) - the 'individual' coping strategies, being behaviourally grounded, are not. This should enable us to examine the workings of both individual and organisational coping mechanisms, with the possibility to develop correspondence between 'classified' ambiguities (typology) with these mechanisms. 
The next section presents a conceptualisation of ambiguity within a general framework, after documenting its treatment in the OM literature. Section 3 provides some empirical illustrations of the properties of our framework through two 'ambiguous' events, the 2011 Thai Flood and 2019/20 Covid-19 pandemic. Section 4 concludes with some implications.

\section{Theoretical Development}

\subsection{Ambiguity}

\subsubsection{Distinct from risk}

March (1994) highlights that risk defines states of the world or situations that can be exhaustively and exclusively specified and can be so as information unfolds over time. An ambiguous situation instead cannot be exhaustively and exclusively stated or that information will bring clarity. Thus, ambiguity can be defined as situations or events whose outcomes and likely occurrence are unclear and cannot be coded with precision (March, 1994, p.178).

This distinction can be further characterised through probabilities and corresponding belief distribution. Risk is a situation where we can assign objective probabilities to outcomes or events. Uncertainty is where we can describe the events but cannot assign objective probabilities (though sometimes subjective probabilities can be assigned). Ambiguity corresponds to a situation where there is not sufficient information to assign objective probabilities and where even a subjective probability distribution cannot be defined uniquely (Friberg, 2015; Takemura, 2014). Hence, ambiguity is quite distinct from risk, which is supported by experimental evidence (Budescu et al., 2002). 


\subsubsection{Situating ambiguity in the OM literature}

Table 1 summarises several ambiguity concepts incorporated in the supply chain literature. The literature search focussed first on so-called 'leading' journals in OM, namely Journal of Operations Management, International Journal of Operations and Production Management, and Production and Operations Management, which was later extended to include International Journal of Production Economics, Journal of Supply Chain Management, Manufacturing and Service Operations Management, and Supply Chain Management: An International Journal. Articles and keywords containing 'ambiguity' was searched and later extended to 'uncertainty', as the latter is often conflated with ambiguity. Each concept is defined, the studies' context explained and any important facet of the treatment of ambiguity noted (see Table 1).

Table 1. Ambiguity in the Supply Chain Context

\begin{tabular}{|c|c|c|c|}
\hline Concept & Definition & Context(s) & Notes \\
\hline $\begin{array}{l}\text { Performance } \\
\text { ambiguity }\end{array}$ & $\begin{array}{l}\text { Difficulty facing decision- } \\
\text { makers (buyers) in } \\
\text { accurately evaluating } \\
\text { (suppliers') performance }\end{array}$ & $\begin{array}{l}\text { Capacity allocation } \\
\text { model \& managing } \\
\text { manufacturer quality }\end{array}$ & $\begin{array}{l}\text { Two studies. } \\
\text { Normative } \\
\text { modelling }\end{array}$ \\
\hline $\begin{array}{l}\text { Information } \\
\text { ambiguity }\end{array}$ & $\begin{array}{l}\text { Interpreting inadequate } \\
\text { information }\end{array}$ & $\begin{array}{l}\text { Product clock-speed and } \\
\text { supply chain integration }\end{array}$ & $\begin{array}{l}\text { Source of } \\
\text { ambiguity }\end{array}$ \\
\hline $\begin{array}{l}\text { Causal } \\
\text { ambiguity }\end{array}$ & $\begin{array}{l}\text { Concerns the ambiguous } \\
\text { nature of causal } \\
\text { connections between } \\
\text { actions and outcomes }\end{array}$ & $\begin{array}{l}\text { Determinants of } \\
\text { knowledge transfer \& } \\
\text { Resource advantage } \\
\text { theory }\end{array}$ & $\begin{array}{l}\text { Two studies. } \\
\text { Normative } \\
\text { modelling }\end{array}$ \\
\hline $\begin{array}{l}\text { Extreme } \\
\text { ambiguity }\end{array}$ & $\begin{array}{l}\text { Decision-makers being } \\
\text { unware that future } \\
\text { scenarios are possible }\end{array}$ & $\begin{array}{l}\text { Sustainable supply chain } \\
\text { management }\end{array}$ & $\begin{array}{l}\text { Ambiguity as } \\
\text { ignorance }\end{array}$ \\
\hline Role ambiguity & $\begin{array}{l}\text { Uncertain about one's } \\
\text { authority and obligations in } \\
\text { a supply chain relationship }\end{array}$ & $\begin{array}{l}\text { Role hazard between } \\
\text { supply chain partners }\end{array}$ & $\begin{array}{l}\text { Institutional } \\
\text { distance as } \\
\text { source of } \\
\text { ambiguity }\end{array}$ \\
\hline $\begin{array}{l}\text { Relational } \\
\text { ambiguity }\end{array}$ & $\begin{array}{l}\text { Understanding of two } \\
\text { businesses operations, } \\
\text { needs and strategies }\end{array}$ & $\begin{array}{l}\text { Adaptation of supply } \\
\text { management \& Buyer- } \\
\text { supplier link }\end{array}$ & $\begin{array}{l}\text { Contractual- } \\
\text { related } \\
\text { ambiguity }\end{array}$ \\
\hline $\begin{array}{l}\text { Processing time } \\
\text { ambiguity }\end{array}$ & $\begin{array}{l}\text { Uncertainty about } \\
\text { probabilities of processing } \\
\text { time }\end{array}$ & $\begin{array}{l}\text { Processing Time } \\
\text { Ambiguity and Port } \\
\text { Competitiveness }\end{array}$ & $\begin{array}{l}\text { Normative } \\
\text { modelling }\end{array}$ \\
\hline $\begin{array}{l}\text { Uncertainty } \\
\text { about } \\
\text { probabilities }\end{array}$ & $\begin{array}{l}\text { Preference for gambling on } \\
\text { known probabilities than } \\
\text { on ambiguous ones }\end{array}$ & Several applications & $\begin{array}{l}\text { Decision-making } \\
\text { definition of } \\
\text { ambiguity }\end{array}$ \\
\hline
\end{tabular}


The OM literature has treated ambiguity as performance ambiguity (Boloori et al., 2020; Cachon and Lariveiere, 2016; Gray and Handley, 2015; Wacker et al., 2016), information ambiguity (Peng et al., 2008), causal ambiguity (Hunt and Davis, 2008; Lawson and Potter, 2012), extreme ambiguity (Silvestre et al., 2015), role ambiguity (Dong et al., 2016), relational/contractual ambiguity (Jia et al., 2016; Kim and Choi, 2015; Steinbach et al., 2018), and processing time ambiguity (Cheon et al., 2017). There are also studies which adhere more closely to the 'uncertainty about probability' definition of ambiguity (Gao et al., 2018; Mak et al., 2014; Natarajan et al., 2012; Wu et al. 2008; Zhang et al., 2016).

The treatment of ambiguity in the OM literature can be summed as follows:

1) Ambiguity's consideration in the supply chain literature is limited. A search of 'uncertainty' reveals far more work on 'supply chain uncertainty' per se (see Simangunsong et al., 2012, 2016). As a further contrast and one noted in the introduction, 'supply chain risk' has spawned a whole sub-field (Kouvelis et al., 2012; Wieland and Wallenburg, 2012). This shows a neglect of ambiguity despite its relevance.

2) While most reviewed studies do treat ambiguity as distinct from risk, some conflate it with uncertainty (Ancarani et al., 2013), or ignorance (Silvestre et al., 2015). As defined above, uncertainty is different from ambiguity. Ignorance or deep uncertainty describe situations where reliable predictions cannot be made because the knowledge base is unreliable (Aven, 2014, p. 162). Ellsberg (1961) suggests that ambiguity could lie between risk and complete ignorance.

3) Ambiguity is quite diversely covered, specific to a context and lacking in coherence. Still taken together this showcases a 'multifaceted' construct. 
4) The 'modelling' pieces are predominantly normative (rational choice) in approach with few studies adopting an explicit behavioural lens (Gao et al., 2018). In fact, not much is reported on the 'sources' of ambiguity, with studies mostly attentive to the non-behavioural sources such as sub-national institutional distance (Dong et al., 2016), supplier protectiveness (Lawson and Potter, 2012), or pre-contractual conditions (Wacker et al., 2016).

\subsubsection{Behavioural decision theory}

Having established how far the neglect of ambiguity goes, we now turn to the conceptualisation of ambiguity. To do so we rely on behavioural decision theory (BDT). BDT is distinguished from normative decision theory, which models the 'desirable' form of decision-making enshrined as 'rational' decision-making (and thus rational choice theory), as being concerned with describing how people 'actually' make decisions (as descriptive decision models) (Takemura, 2014).

One of the tenets of BDT that makes it distinct is recognising human cognition. Several consequences arise as a result. One is in terms of 'optimising' behaviour, treasured by normative models, that can be altered. As opposed a reasoned optimising behaviour (maximising or minimising), 'satisficing' human behaviour can be observed, where decision-makers are content with non-optimal choices or choose options they deem acceptable (Davis, 2019; Takemura, 2014). Another significant difference is the resulting 'cognitive biases' and thus sub-optimal decisions (Davenport, 2020; Roberto et al., 2006). 


\subsubsection{Typology of ambiguity}

Next, we draw on behavioural decision theory's treatment of ambiguity to develop a typology of ambiguity in the supply chain context, which is a more coherent take on ambiguity. There are four groupings:

1) Interpretative ambiguity. Ambiguity in its simplest form implies a situation being open to more than one interpretation, with an unambiguous situation described as having clear understanding as it has one meaning. As organisational life is about sense-making of situations or events, it is quite possible that multiple inconsistent interpretations of situations/events are developed (March, 1994, p. 184). Role ambiguity can be regarded as arising due to a lack of clarity subject to different meanings. It may rise when a supplier is unsure about the means available for it to terminate contracts with distributors (Dong et al., 2016), which could be due to inconsistent 'interpretations' of its power to do so.

2) Causal ambiguity. The nature of causal connections between factors are often difficult to untangle (Bendoly, 2015; March, 1988, p. 337). For example, the link between supply chain factors or same factors with performance could be unclear. Causal ambiguity could manifest itself in the supply chain context where an organisation is unable to determine how it has achieved a competitive advantage as a result of some purchasing activity (Hunt and Davis, 2008), or it could be a lack of understanding of the linkages between inputs and outputs as related to a supplier's knowledge (Lawson and Pottter, 2012).

3) Evaluative ambiguity. This type of ambiguity is about decision-makers' assessment of situations (including impact and outcomes). For example, ambiguity could arise in connections to a supplier's performance, the quality of 
its performance, and processing performance (Cheon et al., 2017; Gray and Handley, 2015; Wacker et al., 2016). Gray and Handley (2015) define quality performance ambiguity as a situation encountered while outsourcing production when it is difficult to ensure product and process specification confirmation and identifying responsibilities if something goes wrong. Thus, there is difficulty of companies in accurately 'evaluating' suppliers' performance.

4) Probabilistic ambiguity. This is the classical type of ambiguity, which encapsulates 'uncertainty about probabilities' and extreme ambiguity (see Table 1). It relates to decision-makers being unsure about the exact likelihood of potential outcomes (Cabantous, 2007). The 'highly improbable' is an example (Aven, 2014), with decision-makers unaware what future scenarios are possible (Silvestre et al., 2015).

\subsubsection{Sources of ambiguity}

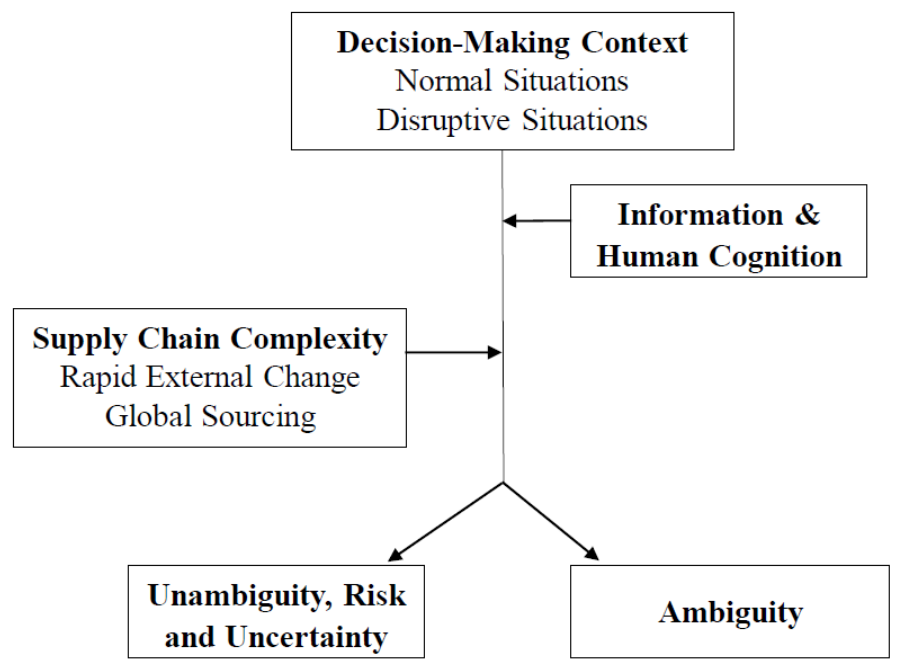

Figure 1. Antecedents of Ambiguous Situations

Figure 1 illustrates the antecedents of ambiguity as connected to the supply chain decision-making context. Two situations can be envisioned: normal and disruptive. A normal situational context describes regular or day-to-day management of an 
enterprise operations. Disruptive situational context depicts a situation where the normal flow of goods and resources in the supply chain is altered. They can be minor or mild on the one hand and turbulent or catastrophic on the other (Craighead et al., 2007; Fiksel, 2015). The former is normally manageable through routine business functions and processes, while the latter can lead to unexpected disruptions to normal business operations (Fiksel, 2015, p. 12). In the extreme there is the highly unpredictable but impactful events that are disruptive to the supply chain and business functions of an enterprise (Gunessee et al., 2018; Knemeyer et al., 2009; Simchi-Levi et al., 2014).

The figure shows for any given situation (normal or disruptive) the decisionmaker (e.g. supply chain practitioner) can face on the one hand decision making under unambiguity (risk and uncertainty) and on the other hand decisions made under ambiguity. The sources that demarcate a situation into unambiguity or ambiguity are two set of factors, information and cognitive factors and supply chain complexity factors. The former are individual or behavioural factors, while the latter are organisational factors.

At the core of what is ambiguity is information. Ambiguity can be attributed to the extant information: through what is available, whether it is missing or incomplete; through its 'lack of clarity' due to possible multiple sometimes conflicting meanings that can be given to the data; or through the newness of the situation such as lack of signals (Budner, 1962). When information is conflicting or 'unknown', it can lead to a lack of resolution on how to proceed. Ambiguity will be 'extreme' if the available information is highly unreliable or conflicting (Aven, 2014).

Information becoming clear and consistent imply: uniquely objective probabilities could be assigned to possible outcomes (turning probabilistic ambiguity 
into risk, as seen in Fig. 1); signals or data being better interpreted to tell coherent stories (March, 1988, p. 395); we can shape the meaning of a decision situation through our evaluation of outcomes to decipher cause from effect. Thus, information in a situational context is a source of ambiguity.

Somewhat connected to information is human cognition, as a behavioural antecedent of ambiguity. People and even organisations are limited in their ability and capacity in processing information because of 'bounded rationality' (Davis, 2019). With such limited cognitive ability, it implies people may not interpret information in a reasoned and logical manner (rationally), or have impaired ability to evaluate evidence and make connections from such evidence to form correct understandings of cause and effect (e.g. interpretative, causal, and evaluative ambiguities). At times people's probabilistic judgements or risk perception are impaired as well due to cognitive limitations, giving rise to probabilistic ambiguity (Bendoly, 2015).

Thus, together information and cognitive factors play a crucial role in giving rise to ambiguity. The fundamental notion of limited rationality is that decisions are made under incomplete information, as not everything can be known (March, 1988, p. 386), implying missing information with limited human cognition magnifies the decisionmaker's difficulty to interpret or evaluate outcomes of situations, assign probabilities to their likely occurrence, or make causal attribution (that is creating interpretative, causal, evaluative and probabilistic ambiguities).

Supply chain complexity is another antecedent of ambiguity. Two factors drive complexity, change in an organisation's external environment and global sourcing. Organisations operate in business environments that are not static, but dynamic and ever changing. With such external environment in a state of flux this generates complexity for an organisation and its supply chain (Silvestre, 2015). Changing 
business environments give rise to ambiguities through gathering and processing of information. This is because organisations may not possess the human resource to continually scour the external environment for information, and/or in complex business environments they need to put in more effort in information processing, due to the large data to process to arrive at a decision (Bosgra, 2008, pp. 175-179).

A second complexity factor is global sourcing. The global nature of supply chains implies greater complexity which in turn creates ambiguity. For instance, global sourcing means having to cope with increased reliance of international supply chain partners, more customer base to serve, supply lead time variability and international transportation (Colicchia et al., 2010; Prater et al., 2001). Accordingly, it has become difficult to 'evaluate' the potential consequences of such global sourcing (evaluative ambiguity).

\subsection{Coping mechanisms}

\subsubsection{Individual approaches}

\begin{tabular}{|c|c|c|c|c|}
\hline Types of Ambiguity & Interpretative & Causal & Evaluative & Probabilistic \\
\hline \multicolumn{5}{|l|}{ Coping Mechanisms } \\
\hline Sense-making & $\begin{array}{l}\text { Editing } \\
\text { Logical Analysis }\end{array}$ & $\begin{array}{l}\text { Attribution } \\
\text { Logical Analysis }\end{array}$ & Framing & $\begin{array}{l}\text { Prob. Judgements } \\
\text { Prob. Weighting }\end{array}$ \\
\hline Tolerance & Avoidance & - & - & Ambiguity Aversion \\
\hline Reference Points & - & - & Status Quo & $\begin{array}{l}\text { Illusion of Control } \\
\text { and Preparedness }\end{array}$ \\
\hline Heuristics & Fast \& Frugal & - & $\begin{array}{l}\text { Availability } \\
\text { Affect } \\
\text { Fast \& Frugal }\end{array}$ & $\begin{array}{l}\text { Availability } \\
\text { Affect } \\
\text { Fast \& Frugal }\end{array}$ \\
\hline
\end{tabular}

Figure 2. Coping mechanisms correspondence with types of ambiguity

Individual coping mechanisms refer to how the individual decision-maker deals with or manages ambiguous situations (Budner, 1962; Kunreuther and Meszaros, 1997). 
Coping as a mechanism is a conscious process that is triggered once an ambiguous decision-making problem/challenge is encountered (Sjödin et al., 2016). There are four ways the decision-maker handles choices made under ambiguity: sense-making; (in)tolerance; reference points (assessment); heuristics. The correspondence between coping mechanisms and ambiguity types is depicted in Figure 2.

Sense-making can be defined as making sense of ambiguous situations by searching for meaning, settling on the plausible explanation and thus coping with ambiguity (Weick et al., 2005). It can take the form of editing, logical analysis, attribution, and framing, as means to cope with interpretative, causal and evaluative ambiguity. Editing is the structuring of available information in a meaningful way to be interpreted, while framing is the subconscious (mental) representations of a decision problem as a means to simplify and make sense of it (Soman, 2004). Attribution refers to assigning meaning to an unclear relationship. Instead, logical analysis is a slow, reasoned and coherent approach to interpret and assess ambiguous data (useful to demarcate cause from effect). Probability judgements and weighting are assessment of probabilities where small probabilities are given more prominence (Davis, 2019).

Tolerance of ambiguity, as a coping mechanism for probabilistic and interpretative ambiguities, reflects the decision-maker's ambiguity attitudes. Tolerance or intolerance to ambiguity is the tendency of the decision-maker of interpreting or perceiving ambiguous situations as desirable and thus opportunities or as threats (Budner, 1962). Ambiguity aversion is a decision maker's attitude to avoid ambiguity, as s/he has a preference for an outcome with known probability over an outcome with unknown probability (Cabantous, 2007; Takemura, 2014). In addition, a decision-maker normally prefers to avoid interpretative ambiguity, when faced with 
limited or multiple meanings from information. When faced with unknown consequences from their choices, decision-makers exhibit both high or low ambiguity aversion (Boloori et al., 2020).

Reference points, as means to deal with evaluative and probabilistic ambiguities, are specific values used to evaluate alternative options (in terms of outcomes or probabilities). The status quo, as the current state/position/view, is a common reference point used by decision-makers. This means decision-making is an exercise to evaluate a decision relative to maintaining the status quo (Kunreuther and Bowman, 1997). Illusion of control and being prepared, as connected to reference points, represent a decision-maker's belief/confidence of being in control and thus wellprepared in his current position, in the face of ambiguity (Schoemaker, 2004).

Heuristics are mental shortcuts that enable decision-makers to make sense of an ambiguous decision-making situation. While there are several heuristics-based rules that govern decision-making, we consider three. Fist, the availability heuristic means making decisions on the basis of what comes to mind and is relevant to the situation. This could be something readily available in the decision-maker's mind, and thus is used to evaluate outcomes or probabilities (Davenport, 2020; Davis, 2019). Second, affect heuristic is a decision-maker being influenced by his/her emotions when making decisions. Positive and negative emotions can lead decision-makers to focus respectively on the potential benefits and losses of their choices (Eckerd and Bendoly, 2015). Finally, fast and frugal heuristics, through recognition or take-the-best, refer to simple short-cuts that use minimum time and knowledge to make quick and adaptive decisions in a situation. It requires limited (recognisable) information search and does not involve much computation (Gigerenzer, 2004). 


\subsubsection{Organisational strategies}

Organisations develop 'coping' strategies to navigate a supply chain world under ambiguity. Drawing from the 'managing supply chain uncertainty' and 'supply chain resilience' literatures (Colicchia et al., 2010; Dabhilkar et al., 2016; Fiksel et al., 2015; Knemeyer et al., 2009; Simangunsong et al., 2012, 2016), two main strategies can be outlined: mitigation; preparedness. Supply chain 'ambiguity-mitigation' strategies comprise of means to reduce fuzziness that permeates ambiguous situations (normal or disruptive). Instead, supply chain 'ambiguity-preparedness' strategies are proactive strategies used by organisations to deal with ambiguous disruptions, whether they are mild or severe. The former comprises of redundancy (holding strategic stocks), capacity (backup facilities/raw materials), lean operations (simplifying process), and postponement (delaying activities) (Dabhilkar et al., 2016; Fiksel et al., 2015).

Preparedness means the enterprise has developed a supply chain that is ready to cope with supply chain disruptions. This can be achieved by building supply chain resilience, which can be defined as the ability to recover, adapt, grow and flourish in the face of uncertain/turbulent change to a supply chain and to return to a desired steady state (Pettit et al., 2013; Fiksel, 2015, p. 10). Resilience is achieved by building capabilities which includes flexibility (e.g. speed and agility in manufacturing, sourcing and order fulfilment) (Fiksel et al., 2015: Prater et al., 2001).

While organisational coping strategies are broadly important in managing SCDM under ambiguity, three specific strategies, collaboration, visibility and organisational learning, play a vital role. Collaboration, as the ability to work effectively with supply chain partners, and visibility, as the enterprise's knowledge of its own operations and environment, as they facilitate information sharing (Pettit et al., 2019), are crucial to 
manage supply chain ambiguity. As a factor that implies informational feedback within the organisation, organisational learning is another important information gathering and ambiguity-coping strategy. Organisations can be better prepared if they learn through experience or from historical disruptions (Dabhilkar et al., 2016), developing 'organisational intelligence' in the process. Such 'experiential learning' can be supportive of the organisation's effort to tame ambiguity, as clarity of information is vital to quantify possible states of the world, such that, demarcating risk from ambiguity (March, 1999).

Therefore, the reason for these strategies importance, is unlike other strategies they go directly to bear on a key source of ambiguity: information. As explained above, ambiguity stems from information incompleteness or from unclear multiple, often, conflicting meanings. Thus, these three factors can be argued contribute to an organisation's supply chain resilience/preparedness, as they affect one of the root causes of ambiguity.

\subsection{Generic framework}

Fig. 3 presents a generic framework for SCDM under ambiguity. It consists of decision and outcomes at one end and situational context at the other end. Situations are normal or disruptive by nature and thus a situation can have an element of ambiguity of various types. They have behavioural and non-behavioural antecedents, the latter which includes supply chain complexity (see Fig. 1). The framework captures coping mechanisms as having a moderating influence, such that a decisionmaker who is influenced by the information available (see Fig. 1), develops coping mechanisms to deal with any ambiguous situation faced (Fig. 2). However, s/he is 'limited cognitively' (human cognition in Fig. 1) to process information made further 
hard with global complex supply chains. At the organisational level coping with ambiguity takes the form of mitigation and preparedness. Organisations attempt to reduce imprecision of a situation or have developed resilience that enable it to better cope, though there is an interplay between individual mechanisms and organisational strategies, when ultimate decisions are taken.

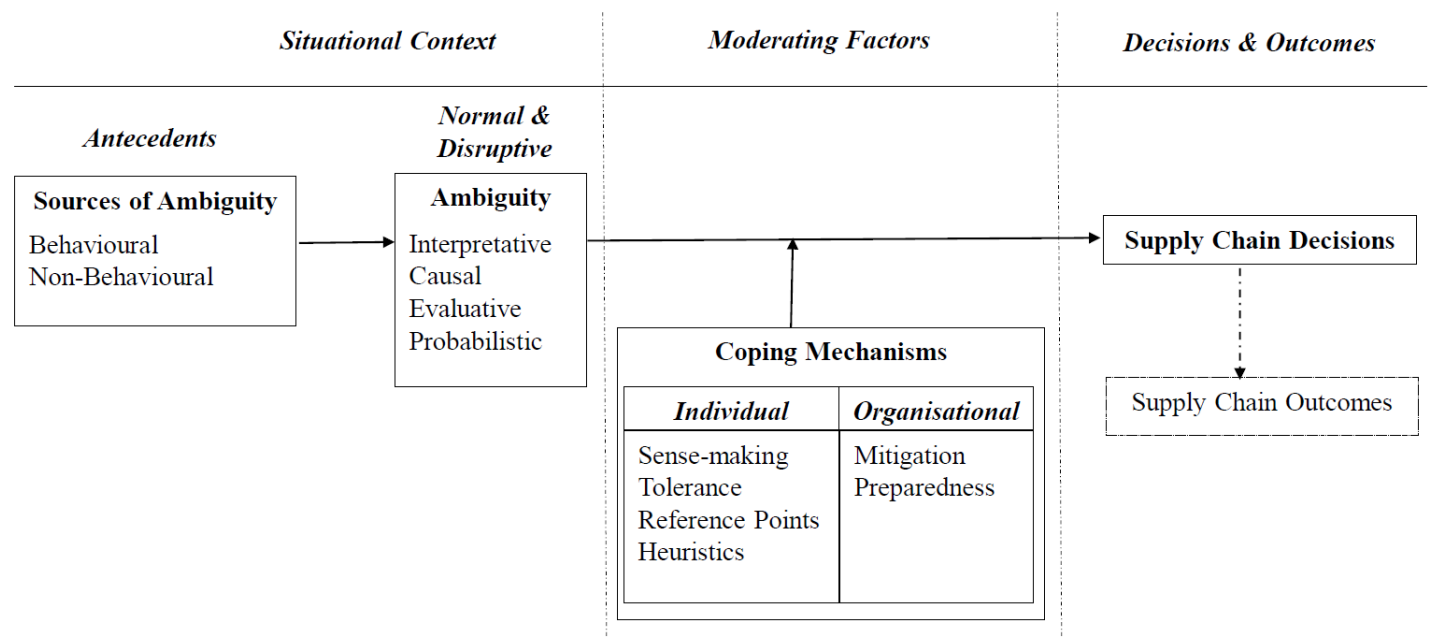

Figure 3. Supply Chain Decision-Making under Ambiguity Framework

Supply chain decision-making. Having examined ambiguity and coping mechanisms separately, we now relate them to SCDM. Decision-making refers to the act of choosing an option from a group of alternatives (Takemura, 2014). In the supply chain context, decisions can be seen as strategic or operational. Strategic supply chain decisions are concerned about designing operations, processes and supply network taking a long-term view, while operational decisions relate to regular activities to match demand and supply. Strategic SCDM includes sourcing, production, facility location, and distribution and logistics decisions, while operational SCDM includes inventory management, demand forecasting, procurement, scheduling and routing decisions (Ivanov et al., 2019). 
Optimising Behaviour, Errors and Biases. Organisations make decisions to optimise specific objectives (Ivanov et al., 2019). These could be shareholder value and profit maximisation or cost minimisation. In the supply chain context, these could be optimising efficiency of any operations and processes, as related to competiveness or costs (Manners-Bell, 2014; Ivanov et al., 2019). Differences in optimising behaviour, in our framework, is brought to the fore by the behavioural antecedents of ambiguity and individual coping mechanisms.

The tenets of normative SCDM models ascribe behaviour to the decision-maker that is more thoughtful, well-reasoned and thus grounded on logical analysis. Such logical thinking would lead to the desired supply chain outcomes following from optimal choices. However, ambiguous data or even limited or non-existent information, imply decision-makers do not necessarily use logical analysis. They develop other 'behavioural' coping mechanisms to deal with ambiguity. In some cases, where the decision-maker uses gut feelings they can arrive at an acceptable 'satisficing' outcome. Similarly, if their tolerance to ambiguity is high, decisionmakers can perceive an ambiguous situation as acceptable and imprecision bearable. In such situational context, they display some risk-taking attitudes, develop 'resiliency' to the situation, and use fast and frugal cues to choose adaptively (Budner, 1962; Gigerenzer, 2004).

Still this state of affairs is unlikely to survive a disruptive situation. During a supply chain disruption, intolerance to ambiguity may prevail. Sense-making with high ambiguity aversion/intolerance can lead to decision errors and biases. Human cognition, as behavioural antecedent, is suggestive of 'cognitive biases' being possible. Cognitive biases are systematic errors in the way decision-makers think and act, and deviations from logical/rational thinking and analysis (Davis, 2019; Roberto 
et al., 2006). A consequence of these biases are sub-optimal decisions (Eckerd and Bendoly, 2015). This could arise from the use of sense-making, heuristics and reference points to navigate ambiguity (Davenport, 2020; Eckerd and Bendoly, 2015), in short, individual coping mechanisms.

Consider an ambiguous situational context where an enterprise uses status quo as reference point. Organisations it is argued tend to be highly sluggish in adjusting to their environments, such that, they often resist change even when faced with ambiguous threats (Kunreuther and Bowman, 1997), developing a preference for the status quo, so-called the status quo bias. Coupled with the illusion of control, decision-makers in organisations can decide 'to do nothing', if they are overconfident of their level of preparedness (Davenport, 2020; Schoemaker, 2004). 'Doing nothing' can also stem from decision-makers subconsciously choosing to ignore the ambiguous, if they have developed a high intolerance to it and perceive it as a threat. All this explains why organisations facing a major supply chain disruption may initially refuse to act. As such, status quo bias and overconfidence (with a dose of ambiguity intolerance), as fallouts of individual ambiguity-coping mechanisms, undermine organisational coping strategies.

Using heuristics is often an intuitive and frugal way of making decisions (Gigerenzer, 2004), which under normal situations can work to cope with ambiguity but under a disruptive context such mental shortcuts can undermine organisational coping strategies. For instance, availability heuristic as a means to deal with evaluative or probabilistic ambiguity, leads decision-makers in organisations to assess an event's frequency or likelihood on the basis of readily available or recalled information (Davenport, 2020; Davis, 2019). In the supply chain context, decision managers may be influenced by press and industry attention given to specific 
disruptive events (Eckerd and Bendoly, 2015). In some cases, when designing operations to be resilient to disruptive situations the decision-maker would normally think of recent 'available' or 'similarly' experienced disruptive situations or what was recently learnt and experienced. While such experiential learning can be virtuous for organisations (Dabhilkar et al., 2016; March, 1999), it can have its limit when human cognition is factored in.

Indeed, the organisational learning literature has recognised the cognitive limit to learning under ambiguity (March and Olsen, 1975). However, the argument made in this paper is this cognitive limit works under the guise of the availability heuristic and for SCDM. In such context, organisational strategies that have been developed to cope with ambiguity can be undermined because of this heuristic. With ambiguous and incomplete information, such learning could lead SCDM astray, meaning the decision-maker is led to think only of those 'experienced' disruptive situations that are frequently-occurring (more likely) and common. This happens when organisations 'myopically' adopt strategies that was shaped by organisational (experiential) learning and focusses only on the 'known' alternatives rather than 'outside the box' alternative means to cope with ambiguity. Yet, what has worked in the past does not necessarily imply would work again, and thus relying on such past experience can lead organisations making sub-optimal supply chain choices. Unlike the received wisdom in the OM literature, this suggests an imperfect role of experiential learning for SCDM under ambiguity (further showing how individual coping mechanisms undermine organisational coping strategies).

SCDM under ambiguity vs. risk. The implications are also different if we are modelling SCDM under ambiguity as opposed risk. Consider, a highly improbable disruption, for which historical data is limited and thus hard to interpret. Thus, risk is 
hard to quantify as assigning probabilities is difficult. This means any risk assessment conducted by companies would be limited to known probabilities and quantifiable (Simchi-Levi et al., 2014). Instead, SCDM under ambiguity recognises this lacuna and the need to consider optimisation of either strategic or operational decision when it is made under the known and 'unknown'.

\subsection{Propositions}

Based on this study's generic framework, the following propositions can be made

Proposition 1. Supply chain decision-making is affected by ambiguity differently from risk (due to its different nature and sources).

Proposition 1.1. Ambiguity's behavioural antecedents affect supply chain decisions distinctively to purely normative (rational-based) supply chain decision-making.

Proposition 2. Ambiguity's effect on supply chain decisions is moderated by individual and organisational coping mechanisms.

Proposition 2.1. Different types of ambiguity have corresponding coping mechanisms.

Proposition 2.2. Individual coping mechanisms can undermine organisational coping mechanisms, leading to sub-optimal choices.

Proposition 2.3. Visibility and collaboration can positively impact supply chain decisions (towards optimal choices) as they facilitate information sharing.

Proposition 2.4. Experiential learning is not always virtuously affecting supply chain decision-making as imperfect learning arise from selective or available experience being used.

\section{Two Ambiguous Events - Illustrative Examples}

\subsection{Background and Data Sources}

The purpose of these illustrative examples is to conduct a 'factual examination' of two events that present features of ambiguity. The two events are, the 2011 Thai flood 
(Event 1) and 2019/20 Covid-19 pandemic (Event 2). Our choice of events is dictated by the fact that natural disasters and pandemics, though disruptive to the supply chain, exhibit differences, such as globalised vs. localised effect, demand vs. supply effects, and actual infrastructural damages (Manners-Bell, 2014). Hence, such a contrast could be revealing about 'ambiguous disruptions'.

Archival information was collected about the events, with the main source of information obtained through Nexis, the well-known business news database. The information was triangulated using archival information from other sources such as company releases, press news, and annual reports. The empircal approach we adopt is studying facts without hypothesis testing, which has been argued can be useful to uncover 'empircial regularities' across different events and contexts (Helfat, 2007).

Furthermore, as one event has passed (Thai Flood) and the other still ongoing at the time of writing (Covid-19), though the archival information allows a 'broad' examination (and comparison), information availability for more 'specific' analysis compels us to resort to a semi-structured design for Event 1 and an unstructured design for Event 2. To be more precise, for Event 1 we study the affected electronics and automotive supply chains (see Haraguchi and Lall, 2015), with a 'focussed' examination of two (affected and non-affected) companies from each industry providing a contrasting perspective, while for Event 2 the medical equipment and drugs supply chains (see Washington Post, 2020), are studied through (unfocussed sampling of) several companies.

We conduct content analysis of collected second-hand archival sources to develop a narrative of facts on properties of our framework. Therefore, the content analysis was guided by the following questions:

- What happened [during the event/ to the supply chain/to the company] 
- Why is the event 'ambiguous'? What are the sources of such ambiguity?

- What 'coping mechanisms' have been used? What specific measures or actions did organisations/individuals take?

By providing organisational and individual levels examination of the two events this enables us to empirically illustrate our framework and its properties. Still, we also document the events at a broader level, which should allow 'generalised' facts to emerge.

\subsection{Event 1 - 2011 Thai Flood}

In 2011 Thailand experienced heavy continuous rainfall which resulted in severe flooding. Though Thailand has been affected by flooding in the past, the 2011 flood was highly unexpected and far more severe. The two industries that were most affected were electronics and automotive (Haraguchi and Lall, 2015; Manners-Bell, 2014).

Table A1 documents in what ways the two supply chains were affected during the Event 1, how it was ambiguous (generally) and how the four organisations coped therein. Each industry presents contrasting cases of one company that was affected (Honda and Western Digital) and one that was not (Nissan and Seagate). Ambiguity can be observed at a 'general' level, with the prevalence of a lack of clarity (unclear signals) and imprecision, with some of these ambiguities being interpretative and evaluative in nature (e.g. unclear interpretation and impact).

Out of the two automotive companies, Nissan's pro-active strategies such as localisation strategies to balance manufacturing and sourcing, and the implementation of scenario planning and risk assessment to periodically evaluate the resilience of its supply chain (in the guise of proactive challenging continuity drills), seem to have 
helped the company cope and prepare for future events. Nissan's Sustainability Reports, published yearly, outlines how the company responded to the 2011 Great East Japan Earthquake and the 2011 Thai Flood by reviewing its business continuity plan and building greater resilience in its supply chain. Similarly, Honda formulated a business continuity plan following these two disasters and revised its crisis response plan into the "Honda Risk Management Rules".

Following Event 1, Western Digital (WD) lost its industry leadership position to Seagate, as it lost market share. Seagate fuelled by its acquisition of Samsung HHD business and using a vertical manufacturing strategy, forged ahead in contrast. Yet, through active leadership and supply chain collaboration, WD was able to bounce back relatively quickly (within 46 days of closure and well ahead of schedule), showcasing the resilience of its supply chain. In fact, within one year its Thai operations were restored to the pre-flood level (Haraguchi and Lall, 2015; Sheffi, 2020).

At a broader level, repercussions and lessons learnt from Event 1 about supply chains disruptions, was that companies with lean (inventory) operations coped less well than companies that had strategic stocks and buffers, such that, redundancy afforded time for supply chains to recover. It is also reported that companies that had resilience in-built through flexibility in sourcing and operations, also coped better. This is because companies having a diversified sourcing strategy were able to shift to alternate location facilities (Haraguchi and Lall, 2015). Furthermore, following the 2011 Great East Japanese Earthquake, some companies used the prior event (for which they were also affected) as a valuable learning experience to build resilience and preparedness (for future disasters). This is indicative of the virtuous role of experiential learning for organisational preparedness (Gunessee et al., 2018). 
Yet a perusal of these companies' annual and sustainability reports reveal a focus on risk. In particular, on what is quantifiable and known; informed by past experience. Nissan's Sustainability Reports is a case in point. While showcasing a well worked "Organization Disaster Recovery", this is geared towards preparedness for an earthquake; informed by a past experience (the 2011 Japanese earthquake to be precise). This can be inferred as business continuity planning informed by the 'availability heuristic' (past occurrence).

\subsection{Event 2 - Covid-19 Pandemic}

Event 2 has had a major disruptive impact on supply chains in almost every industry worldwide, thus epitomising 'extreme ambiguity' at work, as both demand and supply were affected. In particular, lacklustre demand and restrictions on movement have created ambiguity for decision-makers at different points of the global supply chains (Bloomberg, 2020; PWC, 2020).

Table A1 provides an overview of how the medical equipment and drugs supply chains have been affected and coping with Event 2. It reveals that companies been operating under a lot pressure and ambiguity, in particular, the supply chain of various medical products, such as respirators, PPE equipment, ventilators, and drugs (Washington Post, 2020). Like for Event 1, Event 2 showcases ambiguity at a 'general' level, with unclear signals, but also interpretative, evaluative and probabilistic ambiguities (the latter pertaining to the reliability of health products). However, the sources of ambiguity are also highlighted (e.g. lockdown, dependence on raw material provider, and complexity).

With Event 2, there has been an increase in demand for medical equipment, leading to a shortage in the face of uncertain demand. This has led to difficulty in 
forecasting demand and resulting in a 'bullwhip effect' consequently. Restrictions on movement across the globe starting with the lockdown in China, has meant input procurement has been affected as well, which has had a 'ripple effect' on the supply chain (Sheffi, 2020; Smith, 2020).

At the same time more specific issues have emerged. First, volatile (reduced) demand due to panic buying and social distancing (Sheffi, 2020). Second, continuity of supply and constraints in procuring key components. Third, labour availability and re-routing due to lockdowns globally (PWC, 2020). Fourth, reliability of medical equipment and coordination within the supply chain, especially with unorthodox suppliers (companies from other industries) answering calls to help out. A case in point is Dyson, the British manufacturer of vacuum cleaners, which according to a BBC news report, found itself with 'no longer required' ventilators it engaged in producing without clear demand.

At the organisational level, coping strategies have taken the form of stockpiling, blended local and global supply chain, greater supply chain visibility and various forms of collaboration (see Table A1). Given ambiguity arises due to various forms of information imperfections (missing or unclear or subject to conflicting interpretation), a strategy of information sharing should aid an organisation.

At the individual decision-making level, Event 2 shows the inadequacies of individual decisions under ambiguity in two ways: risk assessment; cognitive biases. First, 'informed' risk identification and assessment while useful in normal situations are less reliable for highly disruptive situations due to limited data. Event 2 exemplifies this. A risk assessment conducted by The Global Fund in March 12 reported mostly 'low to moderate' operational risk for various assessed areas of the global health product supply chains, while fast forward to its report on May 25 this 
risk assessment was now noted as moderate, such that it now expects delays for every order (see The Global Fund, 2020). Similarly, the Institute for Supply Management's Survey about Covid-19's global supply chain disruptions documented the fact that in 'early March more than 80 percent believed their organization would experience some impact due to COVID-19 disruptions. By the end of March, this increased to 95 percent of organizations who will be or have already been impacted by coronavirus' (ISM, 2020).

It has been noted that Event 2 as an ambiguous event exhibited several cognitive biases that usually plague decision-making (Alexander, 2020; Chaxel, 2020; Davenport, 2020; Smith, 2020). We summarise two here.

Status quo bias and overconfidence. In the early stages of Event 2, many organisations failed to act, mainly due to their unwillingness to change, with anything shifting them from their status quo point seen as a loss (Davenport, 2020). The illusion of control and that companies were somewhat prepared for this eventuality, can further explain such inaction, suggesting an element of overconfidence. Echoing the above reported surveys by the ISM and the risk assessment of The Global Fund, but as a broader attitude, companies initially felt Event 2 "would not be major disruption - and that even if it were, we would be ready to confront it" (Chaxel, 2020).

Availability heuristic and imperfect learning. Event 2 being complex and multifaceted, meant to better understand it people focussed on what was readily 'available' and accessible, through massive media coverage (Davenport, 2020). For supply chain decision-makers they used learning from experience to mitigate 
prevailing ambiguity. Thus, regularly gathering information and interpreting it, has allowed decision-makers to chart and improve their course of action (Chaxel, 2020).

While feedback learning should help with 'mitigation' (at the time of occurrence), experiential learning for 'preparedness' by learning from historical data highlights the truism of Proposition 2.4; that experiential learning is imperfect if it is based on availability heuristic. Indeed, while the occurrence of pandemics has been deemed as small but non-negligible (Manners-Bell, 2014), its probability of occurrence and all contingency planning has been based on a 'flu-pandemic' and not a 'coronavirus-pandemic'. Reasoning behind this is the flu-pandemic has been estimated more likely than a coronavirus-pandemic, based on past occurrence and thus what consequently is more likely. Not surprisingly, as a 'preventive' measure, this led to the stockpiling of 'flu' vaccines (Alexander, 2020).

\subsection{Summative facts}

Based on the stylised facts we observe across the two events and various affected supply chains therein, we conclude

Fact 1: Disruptions can be interpreted as ambiguous if the types and antecedents of ambiguity are observed (as being salient in the situational context).

Fact 2: Decision-makers during disruptions exhibit cognitive biases due to ambiguous (limited) data, with risk assessment highly inadequate.

Fact 3: Visibility and collaboration help with information sharing and reduce information incompleteness and ambiguity about a disruption, but organisational learning is limited in its positive influence, as enterprises' preparedness is geared towards the known or quantifiable. 


\section{Conclusions}

The main implications of this work are theoretical in nature. First, at a broader level is our contribution to behavioural OM (Donohue et al., 2019, 2020), which explicates a 'descriptive' SCDM framework under ambiguity. This study has shown that incorporating ambiguity, with behavioural foundations, in the supply chain context makes a difference. SCDM is quite distinct when conceptualised with than without ambiguity, whether seen through the behavioural antecedents or individual coping mechanisms. The propositions derived from our generic framework highlight this distinctiveness.

Second, our paper develops a typology of ambiguity, categorised as, interpretative, causal, evaluative and probabilistic. These ambiguity types have a correspondence with specific individual 'coping' mechanisms, namely, sense-making, tolerance, status quo referencing and heuristics. It also shows how individual coping mechanisms can undermine organisational 'coping' strategies, leading to sub-optimal choices. For example, an intolerance or aversion to probabilistic ambiguity can lead to an unwillingness to recognise and even underestimating it, and an illusion of control and being prepared, lead to the catastrophic decision to 'do nothing'.

Third, our framework reveals the positive role of visibility and collaboration in the supply chain context to cope with information incompleteness as a source of ambiguity. However, perhaps the most striking insight is that of imperfect organisational 'experiential' learning. This arises due to the decision-maker's predilection for availability heuristic, which implies the use of common 'similar' experiences and at times what is known, through updated priors.

The properties of our framework was assessed through two ambiguous events, 2011 Thai Flood and 2019/20 Covid-19, empirically illustrating its value to further 
our understanding of SCDM under ambiguity. Three main facts were documented: that disruptions do highlight features of ambiguity in the global supply chain; that decision managers during disruptions do exhibit cognitive biases; and that, organisational strategies of visibility and collaboration allow organisations to better cope with ambiguity but organisational learning is limited due to availability heuristic.

In terms of practical implications of this work, there is a need for companies to plan not for risk but ambiguity. Far too often enterprises think in terms of supply chain risk management (SCRM). This study emphasised the problematic issue with this framework as being too reliant on the probabilistic approach; risk and the known.

Alternative approaches could be explored. These include balancing alternative approaches with the probabilistic approach that uses 'interval' probabilities and 'robust' approaches that encompass threats, opportunities and the unforeseen (Aven, 2014, p.163). Then, scenario planning and simulated exercises could be broached. For instance, planning for different scenarios where ignorance or unknown unknowns subsist may help gain intelligence in preparing for unforeseen contingencies. Such planning could develop scenarios of states of the world with different likelihood and information sets, connected to distinct types of ambiguity (e.g. interpretative or probabilistic) and normal and disruptive situational contexts (Friberg, 2015, pp. 160161; Schoemaker, 2004).

However, all of these need to factor in the fact that decision-makers are prone to errors and biases whether when they evaluate situational outcomes or making judgements about occurrence of events. Coping strategies at the organisational level far often eschew the human factor; a supply chain however robust or resilient, can be undermined by decision-makers' penchant to use heuristics and subsequently by cognitive biases (Davenport, 2020; Roberto et al., 2006). 
In this optic to make 'better' decisions when supply chains are ambiguous (and under strain), organisations could rely on greater visibility and cooperative strategies geared towards gathering data to feed into more effective scenario planning under ambiguity, at the organisational level. However, at the individual level there is a need to better interpret such information (sense-making), whether through critical thinking, expert judgement and group decision-making. During major disruptions, smarter decisions can be made by using the so-called 'fishbowl' approach, where apart from usual decision-makers and experts, other people are involved as observers and are invited in when they have ideas to share (Alexander et al., 2020).

Furthermore, at an even very basic level there is a need to educate executives and supply chain practitioners about our probabilistic world, biases and representations (see Larrick, 2004). A training program of 'scenario planning under ambiguity' that coaches about types of ambiguities and coping mechanisms, in particular the use of judgements, heuristics and logical analysis under different scenarios of an ambiguous world is needed.

\section{References}

Alexander, A., De Smet, A. and Weiss, L. (2020), "Decision in Uncertain Times", McKinsey \& Company, March 24.

Alexander, S. (2020), “A failure, but not for prediction”, Slate Star Codex Blog, April, 24.

Ancarani, A., Di Mauro, C., D’Urso, D. (2013), “A human experiment on inventory decisions under supply uncertainty", International Journal of Production Economics, Vol. 142, pp. 61-73.

Aven, T. (2014), Risk, Surprises and Black Swans: Fundamental Ideas and Concepts in Risk Assessment and Risk Management, Routledge, New York, NY.

Bendoly, E. (2015), "Synch and Swim: Managing and Mismanaging Process Constraints and Variability", Bendoly, E., Wezelm W.V. and Bachrach, D.G. (Eds). The Handbook of Behavioral Operations Management: Social and Psychological Dynamics in Production and Service Settings, pp. 33-43.

Bloomberg (2020). Battered and Bruised, Supply Chains Shift to Recover-and-Survive Mode. April 26.

Boloori, A., Saghafian, S., Chakkera, H.A. and Cook, C.B. (2020). "Data-Driven Management of Post-transplant Medications: An Ambiguous Partially Observable 
Markov Decision Process Approach", Manufacturing \& Service Operations Management, forthcoming.

Bosgra, S. (2008), Cognitive Complexity, industry dynamism and risk taking in entrepreneurial decision-making, (Eds) Vermeulen, P.A.M. and Curseu, P.L., Entrepreneurial Strategic Decision-Making: A Cognitive Perspective, pp. 175-190, Edward Elgar, Cheltenham, UK.

Budescu, D.V., Kuhn, K.M., Kramer, K.M. and Johnson, T.R. (2002), "Modeling certainty equivalents for imprecise gambles", Organizational Behavior \& Human Decision Processes, Vol. 88, pp. 748-768.

Budner, S. (1962), "Intolerance of ambiguity as a personality variable", Journal of Personality, Vol. 30 No.1, pp. 29-50.

Cabantous, L. (2007), “Ambiguity aversion in the field of insurance: insurers' attitude to imprecise and conflicting probability estimates", Theory \& Decision, Vol. 62, pp. 219-240.

Cachon, G.P. and Lariviere, M.A. (2016), "Capacity allocation using past sales: When to turn and earn”, Management Science, Vol. 45 No. 5, pp. 685-703.

Chaxel, A-S. (2020), "How Do Governments and Individuals Make Decisions in A Time of Crisis? The Case of the Coronavirus", Knowledge@HEC, HEC Paris.

Christopher, M. and Peck, H. (2004), "Building the resilient supply chain", International Journal of Logistics Management, Vol. 15 No. 2, pp. 1-13.

Cheon, SH., Lee, C-Y. and Wang, Y. (2017), "Processing Time Ambiguity and Port Competitiveness", Production \& Operations Management, Vol. 26, No. 12, pp. 2187-2206.

Chopra, S., Sodhi, M.S., (2004), "Managing risk to avoid supply chain breakdown", MIT Sloan Management Review, Vol. 46 No. 1, pp. 53-61.

Colicchia, C., Dallari, F. and Melacini, M. (2010), "Increasing supply chain resilience in a global sourcing context", Production Planning and Control: The Management of Operations, Vol. 21 No. 7, pp. 680-694.

Craighead, C.W., Blackhurst, J., Rungtusanatham, M.J. and Handfield, R.B. (2007), "The severity of supply chain disruptions: design characteristics and mitigation capabilities", Decision Sciences, Vol. 38 No. 1, pp. 131-156.

Dabhilkar, M., Birkie, S.E. and Kaulio, M. (2016), "Supply-side resilience as practice bundles: a critical incident study", International Journal of Operations \& Production Management, Vol. 36 No. 8, pp. 948-970.

Davenport, T.H. (2020), "How to Make Better Decisions About Coronavirus", MIT Sloan Management Review, Column, April 8.

Davis, A.M. (2019), "Biases in Individual Decision-Making”, Donohue K, Katok E, Leider S. (Eds). The Handbook of Behavioral Operations, Wiley, Hoboken, NJ, pp. 151-198.

Dhami, S. (2016), The Foundations of Behavioral Economic Analysis, Oxford University Press, Oxford.

Dong, M.C., Ju, M., Fang, Y. (2016), "Role hazard between supply chain partners in an institutionally fragmented market", Journal of Operations Management, Vol. 46, pp. 5-18.

Donohue, K., Katok, E. and Leider, S. (2019), The Handbook of Behavioral Operations, Wiley, Hoboken, NJ.

Donohue, K., Özer, Ö and Zheng, Y. (2020), "Behavioral Operations: Past, Present, and Future", Manufacturing \& Service Operations Management, Vol. 22 No. 1, pp. 191-202. 
Eckerd, S. and Bendoly, E. (2015), "The Study of Behavioral Operations", Bendoly, E., Wezelm W.V. and Bachrach, D.G. (Eds). The Handbook of Behavioral Operations Management: Social and Psychological Dynamics in Production and Service Settings, pp. 33-43.

Ellsberg, D. (1961), "Risk, Ambiguity and the Savage Axioms", Quarterly Journal of Economics, Vol. 75 No.4, pp. 643-669.

Fiksel, J. (2015), Resilient By Design: Creating Businesses That Adapt and Flourish in a Changing World, Island Press, Washington, DC.

Fiksel, J., Polyviou, M., Croxton, K.L., Petit, T.J. (2015), "From risk to resilience: Learning to deal with disruption”, MIT Sloan Management Review, Vol. 56 No. 2, pp. 79-86.

Friberg, R. (2015), Managing Risk and Uncertainty: A Strategic Approach, MIT Press, Massachusetts.

Gao, Y., Driouchi, T. and Bennett, D.J. (2018), “Ambiguity aversion in buyer-seller relationships: A contingent-claims and social network explanation", International Journal of Production Economics, Vol. 200, pp. 50-67.

Gigerenzer, G. (2004), "Fast and Frugal Heuristics: The Tools of Bounded Rationality", Koehler, D.J. and Harvey, N. (Eds). Blackwell Handbook of Judgment and Decision Making, Blackwell Publishing, UK, pp. 62-88.

Gino, F. and Pisano, G. (2008), "Toward a theory of behavioral operations", Manufacturing \& Service Operations Management, Vol. 10 No. 4, pp. 676-691.

Gray, J.V. and Handley, S.M. (2015), "Managing contract manufacturer quality in the presence of performance ambiguity", Journal of Operations Management, Vol. 38 pp. 41-55.

Gunessee, S., Subramanian, N. and Ning, K. (2018), "Natural disasters, PC supply chain and corporate performance", International Journal of Operations \& Production Management, Vol. 38 No. 9, pp.1796-1814.

Haraguchi, M. and Lall, U. (2015), "Flood risks and impacts: A case study of Thailand's floods in 2011 and research questions for supply chain decision making”, International Journal of Disaster Risk Reduction, Vol. 14, pp. 256-272.

Helfat, C.E. (2007), "Stylized facts, empirical research and theory development in management", Strategic Organization, Vol 5 No. 2, pp. 185-192.

Hunt, S.D. and Davis, D.F. (2008), "Grounding supply chain management in resource-advantage theory", Journal of Supply Chain Management, Vol. 44 No. 1, pp. $10-21$.

ISM (2020), “Covid-19 Global Supply Chain Disruptions Continue”, Institute for Supply Management, Tempe Arizona, April 14.

Ivanov, D., Tsipoulanidis, A. Schönberger, J. (2019), Global supply Chain and Operations Management, $2^{\text {nd }}$ Edition. Springer, Switzerland.

Jia, F., Gao, R., Lamming, R. and Wilding, R. (2016), "Adaptation of supply management towards a hybrid culture: the case of a Japanese automaker", Supply Chain Management: An International Journal, Vol. 21 No. 1, pp.45-62.

Kim, Y. and Choi, T.Y. (2015), "Deep, sticky, transient, and gracious: an expanded buyer-supplier relationship typology", Journal of Supply Chain Management, Vol. 51 No. 3, pp. 61-86.

Knemeyer, A.M., Zinn, W. and Eroglu, C. (2009), "Proactive planning for catastrophic events in supply chains", Journal of Operations Management, Vol. 27 No. 2, pp. 141-153. 
Kunreuther, H. and Bowman, E.H. (1997), "A Dynamic Model of Organizational Decision Making: Chemco Revisited Six Years After Bhopal”, Organization Science, Vol. 8 No. 4, pp. 404-413.

Kunreuther, H. and Meszaros, J. (1997), "Organizational choice under ambiguity: Decision making in the chemical industry following Bhopal", Shapira, Z. (Ed.). Organizational Decision Making, Cambridge University Press, Cambridge, UK, pp. 61-80.

Larrick, R.P. (2004), "Debiasing”, Koehler, D.J. and Harvey, N. (Eds). Blackwell Handbook of Judgment and Decision Making, Blackwell Publishing, UK, pp. 316337.

Lawson, B. and Potter, A. (2012), "Determinants of knowledge transfer in inter-firm new product development projects", International Journal of Operations \& Production Management, Vol. 32 No. 10, pp.1228-1247.

Mak, H-Y and Shen, Z-J.M. (2014), "Pooling and Dependence of Demand and Yield in Multiple-Location Inventory Systems", Manufacturing \& Service Operations Management, Vol. 16 No. 2, pp. 263-269.

Manners-Bell, J. (2014), Supply Chain Risk: Understanding Emerging Threats to Global Supply Chains, Kogan Page, London.

March, J. (1988), Decisions and Organizations, Blackwell Publishers, UK.

March, J. (1994), A Primer on Decision Making: How Decisions Happen, Free Press New York, NY.

March, J. (1999), The Pursuit of Organizational Intelligence: Decisions and Learning in Organizations, Blackwell Publishers, UK.

March, J. and Olsen, J.P. (1975), "The uncertainty of the past: Organizational learning under ambiguity", European Journal of Political Research, Vol. 3 No. 2, pp. 147171.

Natarajan, K., Sim, M. and Teo C-P. (2012), "Beyond Risk: Ambiguity in Supply Chains", (Eds) Kouvelis, P., Dong, L., Boyabatli, O. and Li, R., The Handbook of Integrated Risk Management in Global Supply Chains, pp.103-124, Wiley, USA.

Peng, D.X., Schroeder, R. and Shah, R. (2008), "Linking routines to operations capabilities: a new perspective", Journal of Operations Management, Vol. 26 No. 6, pp. 730-748.

Pettit, T., Fiksel, J. and Croxton, K. (2013), "Ensuring Supply Chain Resilience: Development and Implementation of an Assessment Tool", Journal of Business Logistics, Vol. 34 No. 1, pp. 46-76.

Pettit, T., Fiksel, J. and Croxton, K. (2019), "The Evolution of Resilience in Supply Chain Management: A Retrospective on Ensuring Supply Chain Resilience", Journal of Business Logistics, Vol. 40 No. 1, pp. 56-6510.

Prater, E., Biehl, M. and Smith, M. (2001), "International supply chain agility: tradeoffs between flexibility and uncertainty", International Journal of Operations \& Production Management, Vol. 21 Nos. 5/6, pp. 823-839.

PWC (2020), "COVID-19: Managing supply chain disruption", PricewaterhouseCoopers LLP.

Roberto, M., Bohmer, R.M.J., Edmondson, A.C. (2006), "Facing ambiguous threats", Harvard Business Review, November, pp. 106-113.

Soman, D. (2004), "Framing, Loss Aversion, and Mental Accounting", Koehler, D.J. and Harvey, N. (Eds). Blackwell Handbook of Judgment and Decision Making, Blackwell Publishing, UK, pp. 370-398.

Schoemaker, P.J.H. (2004), "Forecasting and Scenario Planning: The Challenges of Uncertainty and Complexity", Koehler, D.J. and Harvey, N. (Eds). Blackwell 
Handbook of Judgment and Decision Making, Blackwell Publishing, UK, pp. 274296.

Sheffi, Y. (2020), “Who Gets What When Supply Chains Are Disrupted?”, MIT Sloan Management Review, Column, May 27.

Silvestre, B.S. (2015), "Sustainable supply chain management in emerging economies: Environmental turbulence, institutional voids and sustainability trajectories", International Journal of Production Economics, Vol. 167, pp. 156169.

Simangunsong, E., Hendry, L.C., Stevenson, M. (2012), "Supply Chain Uncertainty: A Review and Theoretical Foundation for Future Research", International Journal of Production Research, Vol. 50 No. 16, pp. 4493-4523.

Simangunsong, E., Hendry, L.C., Stevenson, M. (2016), "Managing supply chain uncertainty with emerging ethical issues", International Journal of Operations \& Production Management, Vol. 36 No. 10, pp.1272-1307.

Simchi-Levi, D., Schmidt, W. and Wei, Y. (2014), "From superstorms to factory fires: Managing unpredictable supply-chain disruptions", Harvard Business Review, January-February, pp. 97-101.

Sjödin, D.R., Parida, V. and Wincent, J. (2016), "Value co-creation process of integrated product-services: Effect of role ambiguities and relational coping strategies", Industrial Marketing Management, Vol. 56, pp. 108-119.

Smith, N. (2020), "Global Supply Chains and Human Behavior Converge During Covid-19 Pandemic", Direct Relief, April 14.

Steinbach, T., Wallenburg, C.M. and Selviaridis, K. (2018) "Me, myself and I: Noncollaborative customer behavior in service outsourcing - the key role of outcome orientation and outcome attributability", International Journal of Operations \& Production Management, Vol. 38 No.7, pp.1519-1539.

Takemura, K. (2014). Behavioral Decision Theory: Psychological and Mathematical Descriptions of Human Choice Behavior. Springer, Japan.

The Global Fund (2020), "COVID-19 Impact on Health Product Supply: Assessment and Recommendations", The Global Fund Covid-19 Latest Information, May 25.

Wacker, J.G., Yang, C., Sheu, C. (2016), "A transaction cost economics model for estimating performance effectiveness of relational and contractual governance: Theory and statistical results", International Journal of Operations \& Production Management, Vol. 36 No.11, pp. 1551-1575

Wagner, S.M. and Bode, C. (2006), "An empirical investigation into supply chain vulnerability", Journal of Purchasing \& Supply Management, Vol. 12 No. 6, pp. 301-312.

Washington Post (2020). Supply chain for medicine is strained, May 3.

Weick, K. E., Sutcliffe, K. M., \& Obstfeld, D. (2005), "Organizing and the process of sensemaking”, Organization Science, Vol. 16 No. 4, pp. 409-421.

Wieland, A. and Wallenburg, C.M. (2012), "Dealing with supply chain risks - Linking risk management practices and strategies to performance", International Journal of Physical Distribution \& Logistics Management, Vol. 42 No. 10, pp. 887-905.

Wu, Y., Loch, C.H. and Heyden, L.H. (2008). "A Model of Fair Process and Its Limits", Manufacturing \& Service Operations Management, Vol. 10 No. 4, pp. 637-653.

Zhang, Y., Shen Z-J.M., Song, S. (2016), "Distributionally robust optimisation of two stage lot-sizing problems”, Production \& Operations Management, Vol. 25 No. 12, pp. 2116-2131. 
Table A1. Ambiguity-coping during the 2011 Thai Flood and Covid-19 supply chain disruptions

\begin{tabular}{|c|c|c|c|}
\hline \multicolumn{4}{|c|}{2011 Thai Flood } \\
\hline $\begin{array}{l}\text { Supply } \\
\text { Chains }\end{array}$ & Specific disruption & Ambiguity & $\begin{array}{c}\text { Coping mechanisms } \\
\text { (Resilience, Preparedness, Mitigation) }\end{array}$ \\
\hline Automotive & $\begin{array}{l}\text { Honda: } \\
\text { Factories inundated, having to } \\
\text { stop production, with } \\
\text { inability to access facility, } 200 \\
\text { suppliers suspended } \\
\text { operations. } \\
\text { Nissan: } \\
\text { Factories were not inundated } \\
\text { but production stopped due } \\
\text { to missing parts. }\end{array}$ & $\begin{array}{l}\text { Honda: } \\
\text { - Unable to make recovery decision due to ambiguous } \\
\text { information. } \\
\text { - Unclear about alternate solution for a safer location } \\
\text { - Timing of parts supply unclear. } \\
\text { - Knock on effect of geo-dispersed activities, with } \\
\text { supply constraints in Thailand creating uncertain } \\
\text { demand bottlenecks for global operations. } \\
\text { Nissan: } \\
\text { - Unclear whether to focus on company's recovery or } \\
\text { focus on brand. } \\
\text { - Unclear with impact of volatile business } \\
\text { environment and global competition. }\end{array}$ & $\begin{array}{l}\text { Honda: } \\
\text { - Recovered after } 174 \text { days } \\
\text { - Created new facility in Indonesia } \\
\text { - Advancement in corrective forecasting helped company to match } \\
\text { supply and demand. } \\
\text { - Alternate sourcing from different countries. } \\
\text { - Collective work with suppliers } \\
\text { Nissan: } \\
\text { - Recovered after } 29 \text { days } \\
\text { - Localisation strategies balancing manufacturing and sourcing } \\
\text { foot print and diversified sources of supply with alternate } \\
\text { facilities in the same country } \\
\text { - New scenarios implemented based on challenging drills to check } \\
\text { the efficacy of measures implemented by global disaster } \\
\text { headquarters. } \\
\text { - Risk assessment before sourcing decisions from the leading } \\
\text { global competitive countries and providing support for } \\
\text { improvement activities after sourcing helped to survive during } \\
\text { disaster. }\end{array}$ \\
\hline Electronics & $\begin{array}{l}\text { Western Digital: } \\
\text { Factories inundated, having to } \\
\text { stop production for } 46 \text { days } \\
\text { from mid-October till late } \\
\text { November } \\
\text { Seagate: } \\
\text { Factories were not inundated } \\
\text { but was affected due to lack of } \\
\text { supplies, affecting the hard } \\
\text { disk drive supply chain }\end{array}$ & $\begin{array}{l}\text { Western Digital: } \\
\text { - Unclear impact with loss of market share due to } \\
\text { manufacturing capacity, and relationship between } \\
\text { pre-flood demand and regaining of market share. } \\
\text { Seagate: } \\
\text { - Interpretation of localised sourcing and its impact on } \\
\text { cost reduction and logistics service improvement. }\end{array}$ & $\begin{array}{l}\text { Western Digital: } \\
\text { - Met increase in demand by surplus inventory within the shortest } \\
\text { time span. } \\
\text { - Active leadership \& investment on people helped to recover fast. } \\
\text { - Spontaneous agreements with suppliers to supply incremental } \\
\text { needs of components for hard disk drive. } \\
\text { Seagate: } \\
\text { - Unaffected component and disk assembly facilities contributed to } \\
\text { performance. } \\
\text { - Vertical manufacturing strategy adopted by the company to } \\
\text { produce critical components on its own, which avoided the } \\
\text { reliance on limited suppliers who were affected by the flood. }\end{array}$ \\
\hline
\end{tabular}




\begin{tabular}{|c|c|c|c|}
\hline \multicolumn{4}{|l|}{ Covid-19 } \\
\hline $\begin{array}{l}\text { Supply } \\
\text { Chains }\end{array}$ & Specific Medical Products & Ambiguity & $\begin{array}{c}\text { Coping mechanisms } \\
\text { (Resilience, Preparedness, Mitigation) }\end{array}$ \\
\hline \multirow[t]{3}{*}{$\begin{array}{l}\text { Medical } \\
\text { Equipment }\end{array}$} & Respirators/Masks & $\begin{array}{l}\text { - Uncertainty due to rising demand of face mask \& } \\
\text { constrained supply. } \\
\text { - Interpretation of how supply affected, securing of } \\
\text { imported raw materials and order fulfilment to } \\
\text { health care providers } \\
\text { - Unclear about estimated inventory levels } \\
\text { - Reliability of masks }\end{array}$ & $\begin{array}{l}\text { - Joint agreement with administration to ensure continuous } \\
\text { supply } \\
\text { - Interactions with administrative leadership } \\
\text { - Added staff, technology, added manufacturing lines. } \\
\text { - Speed - premium for manufacturers to retool production lines } \\
\text { - Forming an alternative network for producing masks with new } \\
\text { car manufacturers. Use of diapers, napkins producers to produce } \\
\text { alternate materials. }\end{array}$ \\
\hline & PPE equipment & $\begin{array}{l}\text { - Authenticity/Reliability of PPE equipment } \\
\text { - Proportion of demand that could be satisfied } \\
\text { - Recall of surgical gowns because of exposure to } \\
\text { bacteria. } \\
\text { - China's lock down reduces capacity throughout } \\
\text { industry }\end{array}$ & $\begin{array}{l}\text { - Creativity and agility in producing needed products such as PPE } \\
\text { during crisis, local sourcing with cooperation of small } \\
\text { manufacturers. } \\
\text { - Network of small buyers created for better coordination } \\
\text { - Use personal network and social media to generate money and } \\
\text { connect people. } \\
\text { - Ramping up capacity } \\
\text { - Open source design to create incubation boxes for health care } \\
\text { - 'Borkers } \\
\text { companies. }\end{array}$ \\
\hline & Ventilators & $\begin{array}{l}\text { - Production for ambiguous demand (answering call } \\
\text { for help without specific customer) } \\
\text { - Unorthodox material suppliers unsure how to } \\
\text { contribute } \\
\text { - Estimating the production run }\end{array}$ & $\begin{array}{l}\text { - Seeking alternate source outside medical supply chain to avoid } \\
\text { conflict } \\
\text { - Using existing network connected to new sources such as } \\
\text { government and distribution channel like Amazon.com }\end{array}$ \\
\hline Drugs & Generic Drugs & $\begin{array}{l}\text { - Drug supply chain is opaque and complex, leading } \\
\text { to full scope of vulnerabilities being unknown } \\
\text { - Dependence on one country (China) for raw } \\
\text { ingredients' in drug manufacturing } \\
\text { - Hard to understand complex supply chain, as } \\
\text { proprietary information held only by few players. }\end{array}$ & $\begin{array}{l}\text { - Greater visibility into the supply chain to better assess risks and } \\
\text { potential disruptions. } \\
\text { - Stock piling, sourcing from more than one supplier } \\
\text { - Planning to develop blended supply chain with local and global } \\
\text { sourcing. }\end{array}$ \\
\hline
\end{tabular}

